Conclusions: Our results demonstrated that a clinically and persistent CAD triples the risk of damage compared to milder or relapsing courses, while hydroxychloroquine appeared to have a "protective" effect. Identifying the prevailing pattern of disease activity in every patient can be translated into a more effective personalized preventing strategy to reduce damage accrual and improve outcomes.

References:

[1] M. Zen et al. Disease activity patterns in a monocentric cohort of SLE patients: a seven-year follow-up study, Clin. Exp. Rheumatol. 30 (2012) 856-863.

Disclosure of Interest: None declared

DOI: 10.1136/annrheumdis-2017-eular.5103

\section{FRI0256 ULTRASOUND CONSENSUS DEFINITIONS ON NORMAL AND ABNORMAL FINDINGS IN SALIVARY GLANDS IN SJÖGREN'S SYNDROME: RESULTS OF AN OMERACT DELPHI PROCESS}

S. Jousse-Joulin ${ }^{1}$, F. Gandjbakhch ${ }^{2}$, S. Ohrndorf ${ }^{3}$, M. Backhaus ${ }^{3}$, G. Tamborrini ${ }^{4}$, I. Chary-Valckenaere ${ }^{5}$, L. Terslev ${ }^{6}$, A. lagnocco $^{7}$, P. Collado ${ }^{8}$, C. Hernandez-Diaz ${ }^{9}$, E. Naredo ${ }^{8}$, W. Schmidt ${ }^{3}$, G. Filippou ${ }^{10}$, C. Dejaco ${ }^{11}$, M. Mortada ${ }^{12}$, A. Hocevar ${ }^{13}$, S. Chrysidis ${ }^{14}$, G. Mardenly ${ }^{15}$, J.J. De Agustin ${ }^{16}$, R. Thiele ${ }^{17}$, D. Mac Carter ${ }^{18}$, S. Finzel ${ }^{19}$, P. Hanova ${ }^{20}$, C. Glaser ${ }^{19}$, D. Hammerfors ${ }^{21}$, M.-A. D'Agostino ${ }^{22}$, G. Bruyn ${ }^{23} .{ }^{1}$ Rheumatology, Hospital, Brest; ${ }^{2}$ Rheumatology, Hospital, Paris, France; ${ }^{3}$ Rheumatology, Hospital, Berlin, Germany; ${ }^{4}$ Rheumatology, Hospital, Basel, Switzerland; ${ }^{5}$ Rheumatology, Hospital, Nancy, France; ${ }^{6}$ Rheumatology, Hospital, Copenhagen, Denmark; ${ }^{7}$ Rheumatology, Hospital, Turin, Italy; ${ }^{8}$ Rheumatology, Hospital, Madrid, Spain; ${ }^{9}$ Rehabilitation, Hospital, Mexico City, Mexico; ${ }^{10}$ Rheumatology, Hospital, Siena, Italy; ${ }^{11}$ Rheumatology, Hospital, Bruneck, Austria; ${ }^{12}$ Rheumatology \& Rehabilitation Department, Hospital, Zagazig, Egypt; ${ }^{13}$ Rheumatology, Hospital, Ljubljana, Slovenia; ${ }^{14}$ Rheumatology, Hospital, Esbjerg, Denmark;

${ }^{15}$ Rheumatology, Hospital, Cairo, Egypt; ${ }^{16}$ Rheumatology, Hospital, Barcelona, Spain; ${ }^{17}$ Rheumatology, Hospital, Rochester: ${ }^{18}$ Rheumatology, Hospital, Whitefish, United States; ${ }^{19}$ Rheumatology, Hospital, Freiburg, Germany;

${ }^{20}$ Rheumatology, Hospital, Prague, Czech Republic; ${ }^{21}$ Rheumatology, Hospital, Bergen, Norway; ${ }^{22}$ Rheumatology, Hospital, Boulogne-Billancourt, France;

${ }^{23}$ Rheumatology, Hospital, MC Groep Hospitals, Lelystad, Netherlands

Background: Ultrasonography (US) of salivary glands (USSG) may support diagnosis and evaluation of disease activity in primary Sjögren's syndrome pSS. In order to extent the use of USSG in daily practice, consensus definitions of normal and abnormal USSG findings are needed.

Objectives: To obtain consensual definitions of normal and abnormal USSG findings using a Delphi process.

Methods: Twenty-seven experts participated in the Delphi process. A Likert scale from 1-5 was used in which 1 indicated complete disagreement and 5 complete agreement. Three core items were proposed: 1 . Consensus of assessment of SG (parotid gland (PG), submandibular glands (SMG), sublingual glands $S L G)$ ). 2. Consensus for elementary lesions of PG, SMG, and SLG changes in PSS patients. 3. Consensus on grading of PG, SM, and SLG in pSS.

Results: The consensus of definitions between experts was reached after three rounds. The results (table 1) showed agreement with more than $75 \%$ of agreement in normal and abnormal definitions in SG and concluded to not evaluate SLG in pSS patients as well as to score pSS SG patients with at least two abnormal glands out of 4 (2 PG and $2 \mathrm{SMG}$ ) with a scoring system $>2$ for each abnormal gland.

Conclusions: We developed a consensual US definition of normal and abnormal USGS findings through a Delphi exercise process. This finding will be used as a basis to further proceed with the validation of USGS for clinical application.

Disclosure of Interest: None declared

DOI: 10.1136/annrheumdis-2017-eular.4976

\section{FRI0257 URINARY ANGIOSTATIN, CXCL4 AND VCAM-1 AS} BIOMARKERS FOR LUPUS NEPHRITIS

C.C. Mok ${ }^{1}$, S. Soliman ${ }^{2}$, L.Y. Ho ${ }^{1}$, F. Mohamed ${ }^{3}$, F.I. Mohammed ${ }^{3}$, C. Mohan ${ }^{2}$ ${ }^{1}$ Medicine, Tuen Mun Hospital, HK, Hong Kong; ${ }^{2}$ Biomedical Engineering,

Abstract FRI0256 - Table 1

\begin{tabular}{|c|c|c|c|c|c|}
\hline (\% of agreement) & Definition of normal US findings & Procedure of scanning & $\begin{array}{l}\text { Definition of abnormal US } \\
\text { findings }\end{array}$ & SG to evaluate in pSS & Definition of scoring \\
\hline Parotid glands & $\begin{array}{l}\text { Uniformly echoic texture with a } \\
\text { clear delineation from the } \\
\text { superficial tissue. Tissue } \\
\text { comparable to thyroid } \\
\text { parenchyma }(81 \%)\end{array}$ & $\begin{array}{l}\text { Longitudinal and transverse } \\
\text { plane }(90 \%)\end{array}$ & $\begin{array}{l}\text { Focal or diffuse an/hypoechoic } \\
\text { areas (95\%) }\end{array}$ & yes & $\begin{array}{l}\text { 4-grade semiquantitative scoring system } \\
\text { (i.e. grade } 0 \text {, normal parenchyma; grade } 1 \text {, } \\
\text { minimal change: grade } 2 \text {, moderate: grade } \\
3 \text {, severe: diffuse inhomogeneity occupying } \\
\text { all the surface of the gland) }(79 \%)\end{array}$ \\
\hline Submandibular glands & $\begin{array}{l}\text { SMG are usually of finer granular } \\
\text { echo texture compared to PG or } \\
\text { to the normal thyroid } \\
\text { parenchyma }(89.1 \%)\end{array}$ & $\begin{array}{l}\text { Longitudinal and transverse } \\
\text { plane }(90 \%)\end{array}$ & Idem PG (95\%) & yes & Idem PG (79\%) \\
\hline Sublingual glands & $\begin{array}{l}\text { SLG has no clear delineation } \\
\text { from the superficial tissue } \\
\text { because of no true fascial } \\
\text { capsule }(77 \%)\end{array}$ & $\begin{array}{l}\text { longitudinal and transverse plane } \\
(77 \%)\end{array}$ & Idem PG (95\%) & no & Not useful \\
\hline
\end{tabular}

University of Houston, Houston, United States: ${ }^{3}$ Rheumatology and Rehabilitation Department, Minya University, Minya, Egypt

Background: Our preliminary proteomic analysis revealed elevated levels of urinary angiostatin, CXCL4 and VCAM-1 in patients with active lupus nephritis Objectives: To study the performance of urinary angiostatin, CXCL4 and VCAM-1 in differentiating between active renal and non-renal SLE. disease, active non-renal disease and inactive disease were randomly recruited, together with a group of healthy controls. Stored urine samples of the participants were assayed for angiostatin, CXCL4 and VCAM-1 and compared among the different groups. ROC analysis was performed to obtain the best cut-off values to calculate the performance of these markers in differentiating among the different groups of patients. SLE disease activity was assessed by the SELENASLEDAI and physician's global assessment (PGA). Specificity and sensitivity of these markers in differentiating between active renal and non-renal SLE was determined by $2 \times 2$ contingency tables. In patients with active renal disease, correlation between these urinary biomarkers with clinical renal parameters was also performed.

Results: 227 SLE patients ( 80 inactive SLE; 67 active non-renal disease; 80 active renal disease; $94 \%$ women, age $39.2 \pm 13.8$ years) and 53 controls were studied. Urinary angiostatin, CXCL4 and VCAM-1 levels normalized for creatinine were significantly higher in patients with active renal than non-renal disease (angiostatin $18.4 \pm 27.1$ vs $1.6 \pm 2.91 \mathrm{pg} / \mathrm{ng} ; \mathrm{p}<0.0001 ; \mathrm{CXCL} 9.11 \pm 15.7$ vs $5.12 \pm 10.4 \mathrm{pg} / \mathrm{ng}$; $\mathrm{p}=0.003$; VCAM-1.41 $\pm 1.31 \times 10^{3}$ vs $\left.0.72 \pm 1.10 \times 10^{3} \mathrm{pg} / \mathrm{ng} ; \mathrm{p}<0.0001\right)$. The levels of these urinary protein markers were also significantly higher in active SLE patients than inactive SLE patients or healthy controls. Urinary angiostatin, CXCL4 and VCAM-1 correlated significantly with the renal SLEDAI (Rho 0.66, 0.45 and 0.51 , respectively; $p<0.001$ in all), total SLEDAI score (Rho $0.60,0.46$ and 0.53 , respectively; $\mathrm{p}<0.001$ in all) and urine protein-to-creatinine ( $\mathrm{UPCr}$ ) ratio (Rho $0.73,0.51,0.59$, respectively; $p<0.001$ ) in all the SLE patients studied. Urinary angiostatin was more specific (specificity 0.82 ) than elevated anti-dsDNA and low C3 (specificity 0.64 and 0.66 ) in differentiating active renal SLE from non-renal SLE. In a subset of patients with biopsy proven active lupus nephritis $(\mathrm{N}=68)$, these urinary protein markers could not differentiate between proliferative (III/IV) from non-proliferative (I/II/V) types of lupus nephritis. However, urinary CXCL4 (Rho $0.25 ; \mathrm{p}=0.049$ ) and VCAM-1 (Rho $-0.28 ; \mathrm{p}=0.02$ ), but not angiostatin (Rho $0.11 ; p=0.39)$, correlated significantly with the histologic activity index. There was no significant association between these protein markers and the histologic chronicity index or renal SLEDAI score. On the other hand, urine angiostatin levels (Rho 0.36; $p=0.003$ ), but not CXCL4 (Rho 0.07; $p=0.59$ ) or VCAM-1 (Rho -0.11; $\mathrm{p}=0.36$ ), correlated significantly with the $u P / C r$ ratio in this subgroup of patients. Conclusions: Urinary angiostatin, CXCL4 and VCAM-1 are potentially useful biomarkers for SLE, in particular lupus nephritis. Further longitudinal studies are necessary to delineate the sensitivity and specificity of these two urinary protein markers in predicting renal flares and prognosis in SLE patients.

Disclosure of Interest: None declared

DOI: 10.1136/annrheumdis-2017-eular.3951

\section{FRI0258 LONG-TERM PROGNOSISOFPATIENTS WITH SYSTEMIC LUPUS ERYTHEMATOSUS-ASSOCIATED PULMONARY ARTERIAL HYPERTENSION: CSTAR-PAH COHORT STUDY}

J. Qian ${ }^{1}$, M. Li ${ }^{2}$, X. Zhang ${ }^{3}$, Q. Wang ${ }^{2}$, J. Zhao ${ }^{2}$, Z. Tian ${ }^{4}$, X. Zeng ${ }^{2}$ on behalf of CSTAR group. ${ }^{1}$ Internal Medicine; ${ }^{2}$ Rheumatology, Peking Union Medical College Hospital, Beijing; ${ }^{3}$ Rheumatology, The People's Hospital of Guangdong Province, Guangzhou; ${ }^{4}$ Cardiology, Peking Union Medical College Hospital, Beijing, China

Background: SLE-associated pulmonary arterial hypertension (PAH) is common in Asian countries, and the clinical outcome of patients with SLE-associated PAH is dramatically impaired.

Objectives: This study aimed to identify the long-term clinical outcomes and prognostic factors of patients with SLE-associated PAH confirmed by right heart catheterization $(\mathrm{RHC})$.

Methods: A multicenter cohort of SLE-associated PAH was established. Baseline and follow-up records were collected. The primary endpoint was death from any
Methods: Patients who fulfilled the ACR classification for SLE with active renal 